\title{
DIGITAL HUMANITIES: A HOLISTIC APPROACH TO CLASSIFY YELLOW COFFINS
}

\author{
S. Mainieri ${ }^{1 *}$, A. Mandelli ${ }^{2}$, C. Rossi ${ }^{2}$ \\ ${ }^{1}$ Museo Egizio, Torino, Italy - stefaniamainieri@gmail.com \\ ${ }^{2}$ Architecture, Built environment and Construction engineering (A.B.C.) Department, Politecnico di Milano, Milano, Italy - \\ (alessandro mandelli, corinna rossi)@polimi.it
}

\section{Commission II}

KEY WORDS: Digital Humanities, Yellow Coffins, Photogrammetry, 3D Survey, Physiognomic, Face Landmark Recognition

\begin{abstract}
The Faces Revealed Project takes its lead from innovative research trends that see the combination of different but interconnected skills and competences. It aims at contributing to the study of ancient Egyptian coffins by developing a new and efficient methodology based on fast, simple, cost-effective, and portable technique allowing the acquisition of precise and accurate gemetric data. This technology will provide further insights into the manufacture, production, workshops, and possibly the ancient reuse of the Yellow Coffins and may also constribute to the creation of a new way of classifying these coffins.
\end{abstract}

\section{INTRODUCTION}

The article summarizes the activities carried out in the first phase of the project 'Faces Revealed: Investigating the faces of Yellow Coffins through photogrammetry. Comparison between 3D model and digital twin for a new analysis of the manufacture, painting techniques and re-use'. The project - financed by the Research and Innovation Programme under the Marie Skłodowska-Curie Grant N. 895130, Horizon 2020, European Union - started in April 2021 in collaboration with the Museo Egizio di Torino, the Department of Near Eastern Language and Culture, University of California, Los Angeles, and the Department of Architettura, Ingegneria delle Costruzioni e Ambiente Costruito, Politecnico di Milano.

The project focuses on the study of Yellow Coffins, a specific class of artifacts that appeared in Thebes at the end of the New Kingdom and were used for more than a millennium, with a peak during the $21^{\text {st }}$ Dynasty (1069-645 BC) (Niwinski, 1988; Taylor, 1989). Their development has been extensively studied (Aston 2009; Niwiński, 1988; Sousa, 2018; Taylor 1989; van Walsem 1997) thanks to the coffins found in the $19^{\text {th }}$ century in two Thebans cachettes which are now stored in several museums around the world (Daressy, 1900; Sousa, 2017; Sousa et al., 2020).

In the past, the scholars focused mainly on the study of layout, iconography, and texts of these objects (Niwiński, 1988; van Walsem, 1997). In the recent years the attention moved towards the production, materials, and painting techniques (Amenta, 2014; Amenta and Guichard, 2017; Dawson and Strudwick, 2016, 2018; Weiss, 2018), as well as the various techniques of execution and the widespread reuse of coffins during the $3^{\text {rd }}$ Intermediate Period (Cooney 2007, 2011, 2014, 2017, 2018a, 2018b). All these studies - including the Faces Revealed Project - are linked by a common task: investigates whether the construction and painting/decorative techniques can be also functional elements to create a typology (Amenta, 2014), against the background of a growing interest on the existence of ateliers and the reuse of objects.

The innovative project focuses on two areas never considered before: the physiognomic traits of the coffin faces without the pictorial 'layer', and the impact and importance of the plaster for the 'modelling' and/or the 'remodeling' of the sculpted wooden masks.
Combining all the data (iconography, texts, layout, morphology and technical aspects) will allow us to isolate comparative models and outline a new, more precise classification of Yellow Coffins and their provenances in terms of workshop and production.

\section{DEVELOPED METHODOLOGY}

Facial features are important elements in understanding the typology and classification of statues. Details such as eyebrows, eye shape, cosmetic lines, ears allowed the scholars to group and date uninscribed statues or identify chronological internal changing in the style and statuary production (Bryan, 1987, 2010, 2015; Hartwig, 2015; Laboury, 2010; Perdu, 2012; Sorouzian, 1999). These elements have rarely been considered in the analysis of Egyptian coffins. However, during the New Kingdom (1550-1069 BC) the anthropoid coffin was the predominant shape of coffin, and it was used throughout all the Egyptian history. The anthropoid shape of the coffin evoked a secondary body and as pointed out by Kathlyn Cooney, 'the depiction of the deceased's face, with open eyes, nose, and mouth carved from wood, was understood to be the means of access between the worlds of the living and the dead. The mummy's actual face would have been directly behind this ideal representation when the corpse was placed into the coffin, and the painting of facial features onto the coffin's surface allowed the dead to see, taste, and smell the living world' (Cooney, 2015). The faces are not only painted on anthropoid coffins, but they also represent together with the hands - the only sculpted trait of these objects, worked separately and then applied to the main structure with the help of wooden tubular pegs.

A further important element to be considered is the difference sometimes quite marked - between the geometrical and the painted facial figures, that is definitely worth being investigated. To this purpose, the photogrammetric approach proves to be costeffective, versatile, and useful since it offers an excellent record of the morphology of the surface allowing to digitally switch off the painted layer. We must consider that, differently from the statues, Yellow Coffins have a complex layering where one material interacts with the other (Weiss, 2018). During the $3^{\text {rd }}$ Intermediate Period (1069-6644 BC) the wood used for coffins was local: sycamore, tamarisk, and acacia woods (Asensi and Amorós, 2017). Differently from the cedar used in the years

\footnotetext{
${ }^{*}$ Corresponding Author
} 
before, Egyptian wood was knotty and had to be pieced together from small scraps through different kind of joints and pegs (Nicholson and Shaw, 2000; Niwinski, 1988; Prestipino, 2017). To smooth out major irregularities of the wooden axes and joints, an overall layer of coarse paste was applied which generally does not lie on the carved wooden surface in a uniform manner.

Often, we can find a large amount of plaster used to help create a curved surface and to give shape to the head, face and upper part of the trunk building up wigs and free-form body features such as ears and breasts (Weiss, 2018). Only after this process a thin layer of white plaster was applied for the painting. So, we must emphasize and underline that the 3D model reveals the surface level of the object that can correspond both to the plaster modelling or to the carved wood. If the face is covered by plaster, the photogrammetry cannot arrive on the level of the wood, this peculiarity is a prerogative of other technologies as X-Ray and CT-scan (Amenta, 2018), but it can give us the physical geometry of the object not always visible at the naked eye because concealed (visually, not physically) by the paint.

For these reasons, photogrammetry is the most suitable technique to start an objective and in-depth morphometric analysis of faces on coffins.

For the project was selected an amount of over one hundred Yellow Coffins dated from $19^{\text {th }}$ to the beginning of $22^{\text {nd }}$ Dynasty and spreads between Musée du Louvre, Paris; Metropolitan Museum of Art, New York; Egyptian Museum, Cairo; Museo Archeologico, Florence; Museo Egizio, Turin; Museo Gregoriano Egizio, Musei Vaticani, Città del Vaticano; Museo Archeologico Nazionale di Napoli; Rijksmuseum van Oudheden, Leiden. For each coffin the study includes:

- high-resolution photogrammetric survey in situ;

- 3D photogrammetric data elaboration;

- autoptic comparison between textured 3D models and solid models to understand whether the pictorial layers correspond to the carving of the face;

- identification of landmarks for measurements on the model without texture (morphometric approach to facial proportion, measurements and grouping);

- database and data connection;

- new typology of Yellow Coffins.

\section{PHOTOGRAMMETRIC SURVEY AND DATA ELABORATION}

From June 2021, 38 Yellow Coffins and 1 mask were examined (Museo Egizio di Torino, Museo Archeologico Nazionale di Napoli, "Museo Egizio" di Firenze, Rijksmuseum van Oudheden in Leiden, Musei Vaticani, Città del Vaticano). The project is focused on faces, but we enlarged the research on the external upper part of coffin lids until the lower part of the arms or, for the stola-coffins (van Walsem, 1997), until the end of the wesekhcollar.

The photogrammetric surveys were performed using a full-frame Nikon D750 camera coupled with a Nikkor $35 \mathrm{~mm} \mathrm{f} / 1.8$ lens and a polarizer to avoid as much as possible reflections and shiny areas. The images were taken at the maximum resolution of 6016 pixels by 4016 pixels. The camera was places on a tripod and the shot was delayed of 5 second to prevent vibration during the acquisition. This also permitted to use low ISO value even in low illuminated museum rooms.

The mean calculated GSD of the photogrammetric survey is around $0,2 \mathrm{~mm}$, since the pixel pitch is $6 \mu \mathrm{m}$ and the distance of acquisition from the object was about $1 \mathrm{~m}$. The acquisition geometry is circular around the object, maintaining the camera as much as possible nadiral to the coffin. The number of images for each artifact is variable considering a transversal overlap of the images of about $79-80 \%$. A pre-calibrated L-shaped bar was places next to the head of the coffin and it was used with a twofold aim: to scale the reconstructed 3D model and to have a reference system useful to define a plane on which the orthophotos were projected (Mandelli et al., 2019).

The photogrammetric elaboration considered the use of Agisoft Metashape 1.7.5 and followed these steps: i) photo-alignment at high resolution; ii) automatic recognition and manual check of circular and cross non-coded targets; iii) scaling; iv) dense cloud reconstruction and data cleaning; v) mesh model; vi) texturing; vii) developing and exporting high-resolution orthophoto, textured and not textured (Figure 1).

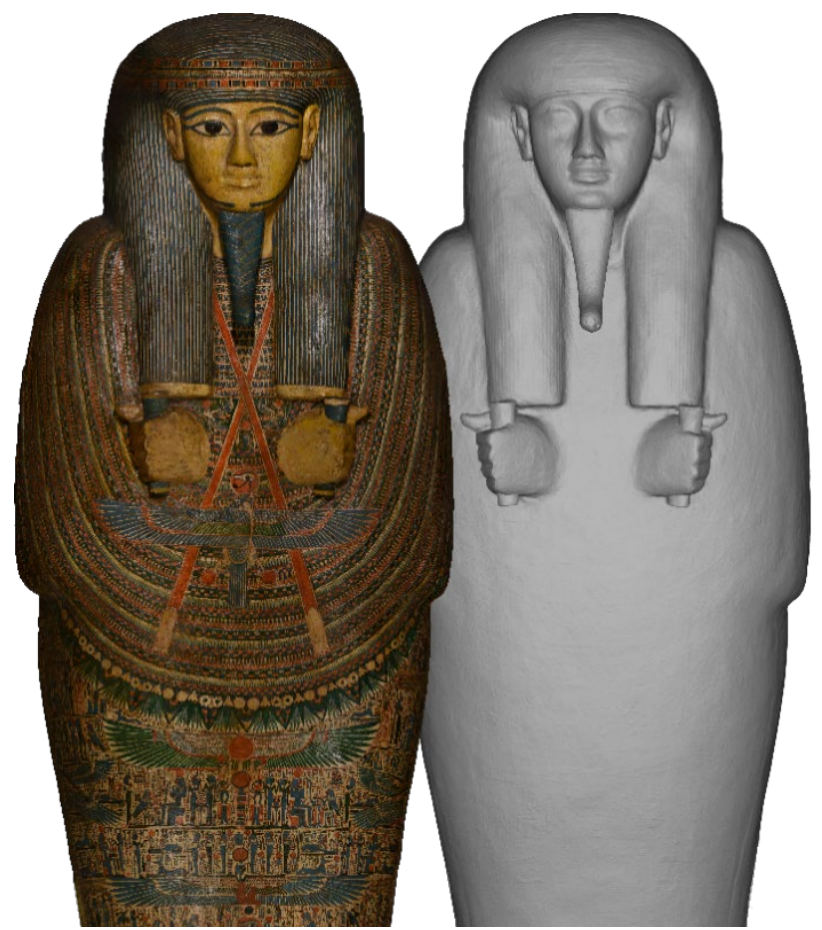

Figure 1. From left to right: orthophoto with and without colour. Inner lid of Djedmontiuefankh, early $22^{\text {nd }}$ Dynasty (CRijksmuseum van Oudheden, Leiden).

\section{COMPARISON BETWEEN TEXTURED AND NOT TEXTURED 3D MODELS}

Once the high-resolution 3D models and orthophotos were elaborated, the analyses of the faces were started. The aim is comparing the 3D models with and without colour and identify the most significative facial landmarks to be measured. For this reason, two different layers have been drawn with the help of various software packages:

- the first layer identifies facial landmarks on the physical geometry (modelled/sculpted traits: form of the face, nose, mouth, eyelids, eyebrows arch, ears - if present) seen from the top, right and left;

- the second layer for the painted features to be drawn (eyes, eyebrows, nose, lips/mouth, chin, ears - if painted), seen from the same projections as before.

These separate layers, by means of CAD software, can be overlapped in transparency on the solid model, on the orthophoto and between them (Figure 2).

This overlapping allows a precise inspection of their correspondence with fixed points. 


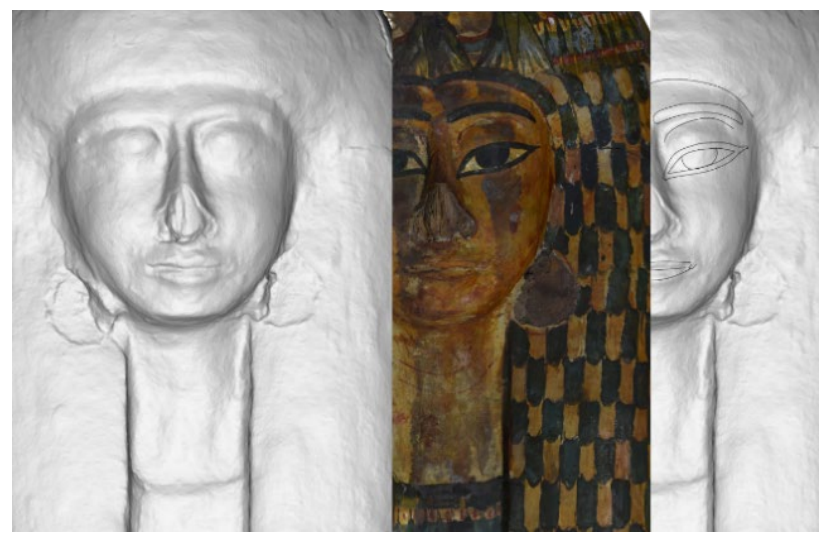

Figure 2. From left to right: greyscale orthophoto, coloured ortophoto, and digitisation of facial features from coloured ortophoto applied onto the greyscale one. Courtesy of the Vatican Coffin Project (CMusei Vaticani).

In this way it is possible to show any possible corrections of the paint applied to sculpted/modelled faces and/or whether they match or not. The comparison between physical geometry and visual appearance of the faces helped the principal investigator of the project to discern and reveal significant discrepancies. First observations showed that faces can be rounded or square, sometimes not symmetrical, or well proportioned; in some cases, the eyes are at different levels, the mouth is out of position regarding the central axis, which can create a distortion of the two halves of the face, or individual features are not placed in the correct relationship to each other.

In one case, the jaw seems to display prognathism; with all the specimens, the eyebrows follow the extension of the line of the nose that continues from the curve of the eyebrows: this curve, however, can be straight and slightly tilted at the ends, rounded or arched; the nose can be thin and proportionate, large at the base or very big; the mouth can be narrow and fleshy, or thin and straight (Figure 3).
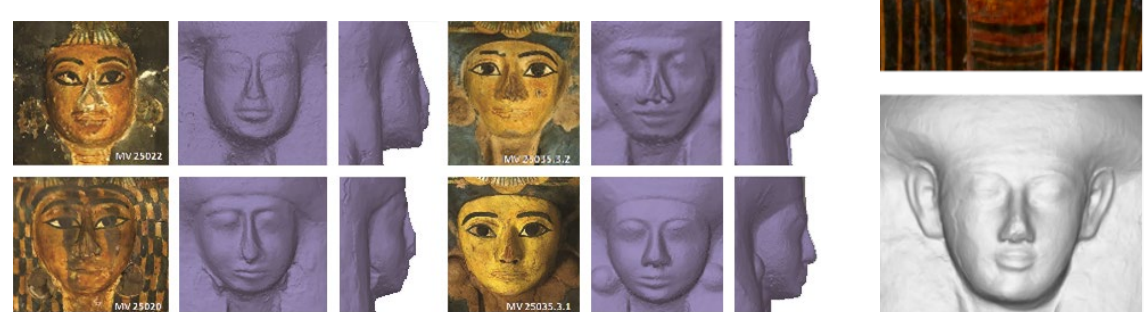

round face (full cheeks; small, round chin; narrow, wide forehead);

ii. square face (wide forehead; square, protruding jaw);

iii. triangular face (high cheekbones; wide forehead; pointed chin);

iv. oval face (wide forehead; shallower jaw; protruding chin).

One of the most important results was to certify how much the paint changes our perception of the object. When we digitally switch off the paint, the appearance of the face changes substantially and in different cases the paint does not correspond to the geometry but remodels/adjusts it. Good examples of these modifications are the coffin set of the scribe Butehamon held at Museo Egizio di Torino, and the coffin set of the Chantress of Amun, Ikhy, in Musei Vaticani.

Museo Egizio di Torino hosts the full coffin set of the scribe Butehamon: outer coffin (CGT 10101.a-b), inner coffin (CGT 10102.a-b) and the mummy board (CGT 10103). The coffins arrived in 1824 with the Drovetti collection and had been probably found in a re-used tomb in Deir el-Medina (TT 291). The coffin represents a male figure with braided (inner coffin and mummy board) or striped (outer coffin) tripartite wig with uncovered, sculpted, and naturalistic ears. All the surface is richly decorated, and the image repertoire combines typical New Kingdom elements with $3^{\text {rd }}$ Intermediate Period theological creations. On the base of the decoration, the coffins fall in 3 different typologies all dated to the beginning of the second half of the $21^{\text {st }}$ Dynasty (990-970 BC ca.) (Niwinski, 1988 and 2004). The set is particularly interesting because we can find similar elements and others very different from each other (Figure 4).
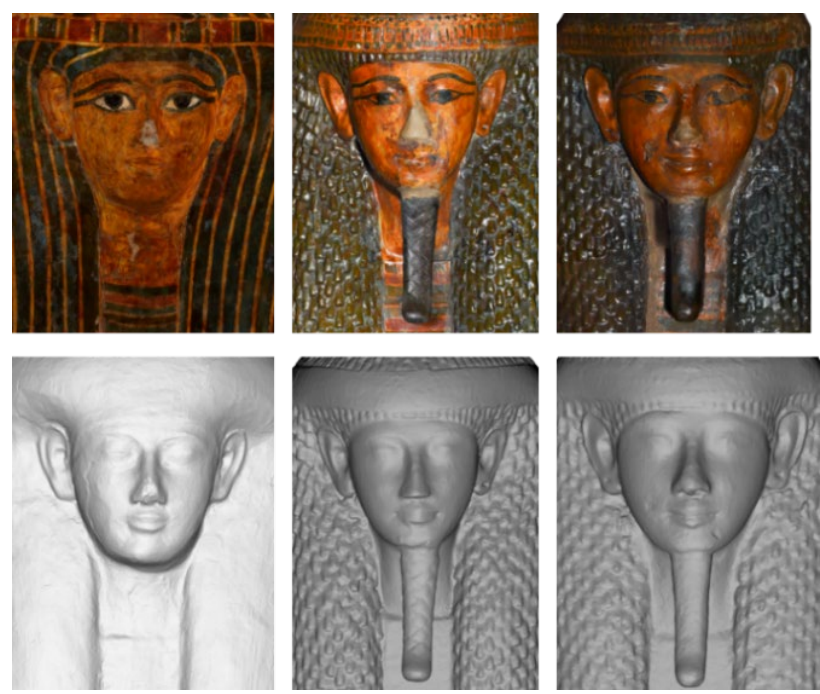

Figure 4. Coffin set of Butehamon with and without texture. From right to left: outer lid (CGT 10101.a), inner lid (CGT 10102.a) and the mummy board (CGT 10103). CMuseo Egizio di Torino.

The faces on the inner coffin and mummy board are very similar both with paint and without. The underlay is well carved and rendered, both the faces are rounded (Type i) even if the inner coffin has gaunt cheeks differently from the mummy board ones. In both cases the eyes are small and symmetrical as well as well proportioned, the nose is straight and thin; the line of the nose is barely outlined and it does not continue in the eyebrows to create a complete arch; the mouths, unpainted, are narrow, smiling and with corners marked by two hollows. On the contrary the face on the outer coffin is oval (Type iv), the eyes are small but different in shape and at different levels (the left eye is higher than the right one); the nose is thin at the root and larger at the base, small and 
rounded ('button nose') and with visible nostrils; the line of the nose continues in the eyebrows which are, full rendered and arched; the mouth, outlined in red, is narrow but straight and without hollows at the corners. Nevertheless, these differences we can observe an important common element: the ears. The ears are big, long and with rounded lobes rendered in a naturalistic way-in all 3 masks. Ears occupy the $2 / 3$ of the face where the lower part of the lobe is in line with the base of the nasal septum and the upper part in line with the line of the headdress. At closer inspection of the geometry, the sculpted ears are bigger than the painted ones: the external part of the ears have been painted in blue, maybe to reduce their form (Figure 5).
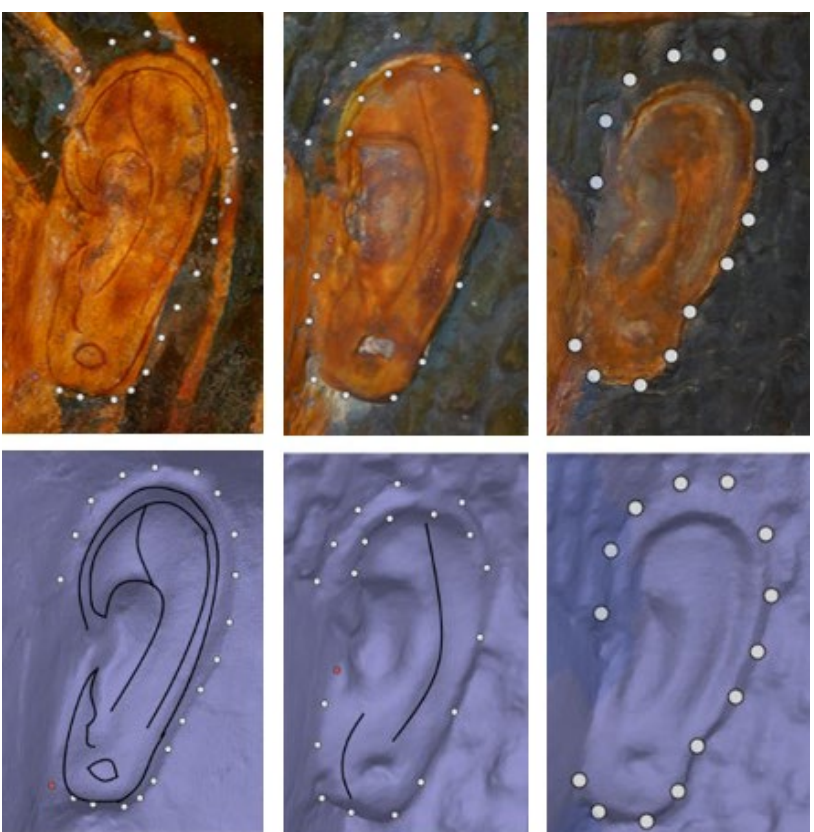

Figure 5. Detail of the left ears of Butehamon's coffin set with and without texture. White dots higlight the geometry that, in the upper part of the ear, does not correspond to the painting.

Why did the painter choose this solution? Is it maybe a trademark of a specific workshop? As the Italian critic art Giovanni Morelli's stated in 1892, 'incidental details of the way a particular artist portrays ears and hands, might be used to attribute unsigned paintings or sculptures to known artists' (Hartwig, 2015). Repeated patterns could correspond to habitual techniques that could be associated with a workshop or individual artist. For the moment the only linked data have been found on two stola coffins dated to the end of $21^{\text {st }} /$ early $22^{\text {nd }}$ Dynasty and stored in Leiden: the inner coffin of Djedmonthuiufankh (RMO, AMM 18-h) (Figure 1) and the mummy board of Penpi (RMO, Ah188).

Another example of how the painting may alter the perception of the geometry is the coffin set of the Chantress of Amun, Ikhy (Musei Vaticani, inv. n. 2035.3.1-3) (Gasse, 1996; Niwiński, 1988; Prestipino, 2017). Dated to the late $21^{\text {st }}$ Dynasty the coffins were offered with by the Khedive of Egypt to Pope Leo XIII in 1894 after the discovery of Bab el-Gasus cache (Sousa et al., 2020). The principal investigator of the project observed that, by studying the painted faces of both artefacts, it is possible to recognize the same painting style and the same colours, which might be indicative of the same workshop or craftsman, or that they were painted at the same time. However, the uniformity in the painted features cannot be observed in the sculpted ones. The geometry of the face, in fact, immediately reveals that the face and physiognomic features of the mask on the mummy board are totally different from the face on the outer coffin (Figure 6).
The mummy board has a more square-shaped face with high cheekbones and a square chin; the nose is long, very large in the lower part, with flared nostrils; the mouth is closed, forming a hint of a smile with well-defined, large, fleshy lips. Conversely, the face of the outer coffin presents fine features with rounded cheekbones, chubby cheeks, and a slightly pointed chin; the nose is small and well-proportioned with 'regular' nostrils, and the mouth, closed too, is linear and fleshy but less than those of the mummy board. Moreover, along with these so different facial features, we note that the mummy board presents a modification of some sculpted elements by means of the paint, possibly made to unify the style of decoration both in the mummy board and the outer coffin. This is evident in the mouth: the paint does not reflect the underlying features, but changes them, from a hint of a smile and a mouth with well-defined, large, fleshy lips to a smaller, closed, unsmiling mouth.
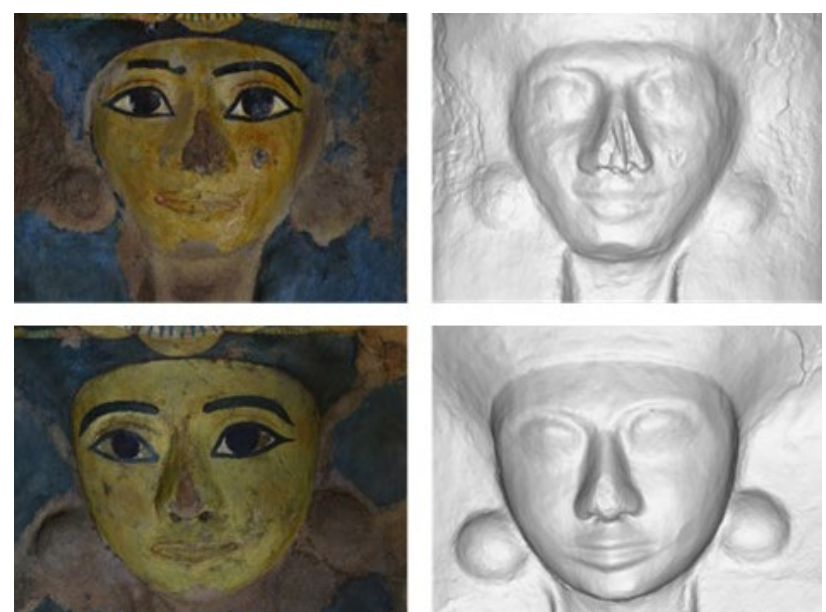

Figure 6. Comparison of digital twins and 3D models of the mummy board of Ikhy (above) and its outer coffin (below). Courtesy of the Vatican Coffin Project (C Musei Vaticani).

\section{IDENTIFICATION OF LANDMARKS}

After the autoptic comparison via points and drawings, the next step of the project is the morphometric approach to facial proportions, measurements, and groupings. All the facial features are measured manually with AutoCAD software, to understand the proportions of the faces. The orthophotos that are not textured allowed the identification of the main landmarks that are fundamental for proportions. Each face is inserted into a grid, which divides it into symmetrical portions (Cartwright and Svoboda, 2020). The main horizontal and vertical lines intersect at the point of the nose so that the face is divided into approximate quarters varying for the different faces. Vertical and horizontal distances represent the variables related to four of the major facial components: eyes, ears, nose, mouth (Figure 7). With the help of this division is possible measure and analyse:

- the face size: as the distance between the midpoint of the hairline and the lowest point of the chin (A-C) or the distance between the endpoints of the left and right cheeks (D-E);

- the eyes: as the distance between outer and inner corner of the eyes fissure (eR2-eR4, eL2-eL4);

- the nose: the maximum height of the nose (near the forehead and eyebrows) until the base of the nasal septum (0-5);

- the mouth/lip: as the distance between the base of the nasal septum and the midpoint of the oral fissure (5- $\beta$ );

- the ears: as the distance between the external point of the ears, in height and width (hR1-hR3; hR1-hR2) and their position. 


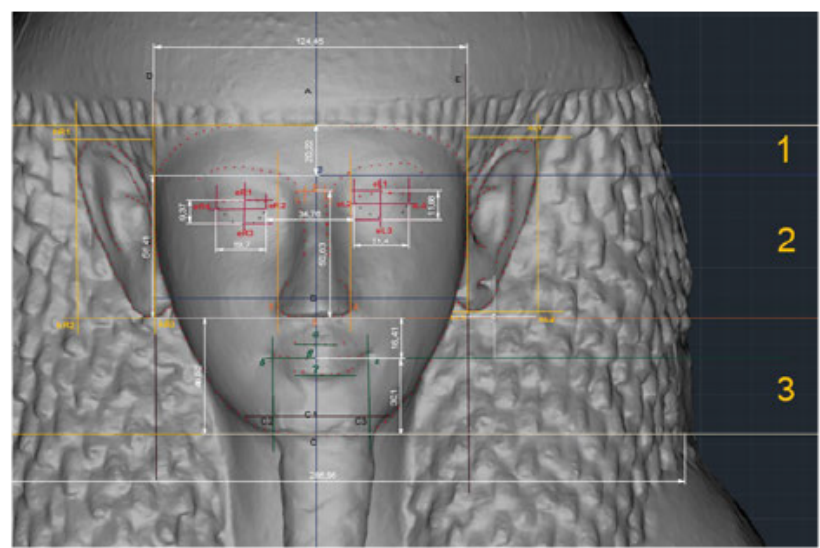

Figure 7. Manual landmarks identification using a fixed grid.

The complexity of the data is recorded and stored into a form that will be used as starting point for the future database that will manage not only the metric, but also the material information of each coffin. The template form is divided into 4 parts with text and images/drawings:

1. general information on the coffin;

2. face:

a. paint;

b. underlayer: morphology and measurements (Table 1); 3. trunk:

a. paint;

b. underlayer: morphology and measurements;

4. photogrammetric evaluation.

A specific vocabulary, especially for the facial traits (illustrated with and without paint) and the variables, will be used for each sector. In this way unique and coherent descriptions for each coffin will be undertaken, which are then useful for grouping and for any possible seriations of the Yellow Coffins.

\begin{tabular}{|l|l|l|l|l|}
\cline { 2 - 5 } \multicolumn{1}{c|}{} & \multicolumn{4}{c|}{ MARKERS } \\
\hline \multirow{2}{*}{ VARIABLE } & & Top & Right & Left \\
\hline $1 / 3$ Face & height & A-C & & \\
\hline & width & D-E & & \\
\hline 2/3 Face & height & A- $\varnothing$ & & \\
\hline 3/3 Face & height & $\varnothing-5$ & & \\
\hline \multirow{2}{*}{ Eyes } & height & $5-\mathrm{C}$ & & \\
\hline \multirow{3}{*}{ Nose } & height & & eR1-eR3 & eL1-eL3 \\
\hline & width & & eR2-eR4 & eL2-eL4 \\
\hline \multirow{2}{*}{ Space Nose-Mouth } & height & $0-5$ & & \\
\hline \multirow{2}{*}{ Mouth } & width & $1-2$ & & \\
\cline { 2 - 5 } & & $3-4$ & & \\
\hline Space Mouth-Chin & $5-\beta$ & & \\
\hline \multirow{2}{*}{ Ears } & height & $\alpha-\gamma$ & & \\
\hline & width & $\delta-\varepsilon$ & & \\
\hline & height & $\beta-\mathrm{C}$ & & \\
\hline & height & & $\mathrm{hR} 1-\mathrm{hR} 3$ & $\mathrm{hL} 1-\mathrm{hL} 3$ \\
\hline & width & & $\mathrm{hR} 1-\mathrm{hR} 2$ & $\mathrm{hL} 1-\mathrm{hL} 2$ \\
\hline
\end{tabular}

Table 1. Measurements for autoptic comparison.

\section{AUTOMATIC EXTRACTION OF FACIAI FEATURES}

In the recent years, remarkable progress has been made in the facial landmark detection domain. Facial landmarks are used to localise and represent salient regions of the face, such as: eyes, eyebrows, nose, mouth and jawline. This research field is very active mainly in the detection of facial features of natural images, however the artistic domain is still widely unexplored. Artistic portraits are quite dissimilar compared to natural faces, in fact they include large style variations in terms of both geometry and texture. Therefore this kind of artistic productions are more complex to analyse. Moreover, datasets that are necessary to train neural networks are unavailable (Yaniv et al., 2019).

Despite these limits, the decision to test an automatic solution for extraction of facial features was taken (Figure 8).

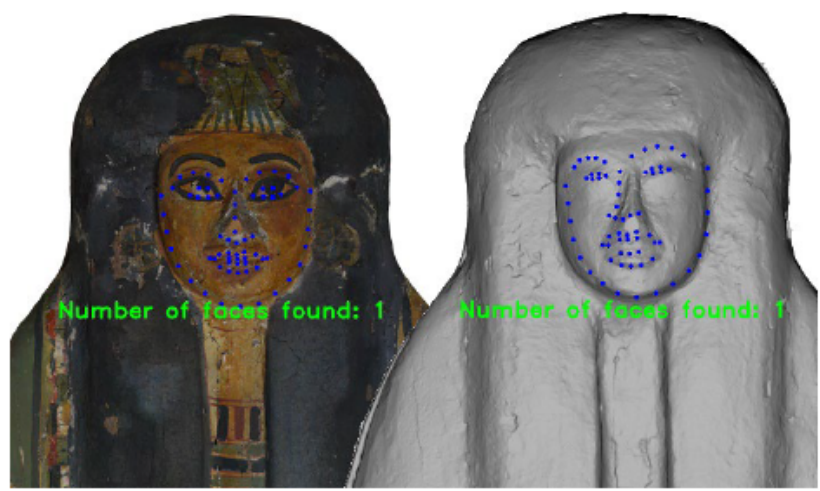

Figure 8. First tests using the face landmark recognition library on coloured and not coloured orthophotos of the same coffin. Courtesy of the Vatican Coffin Project (을 Musei Vaticani).

Considering the number of coffins already surveyed and the ones that are still to be recorded, these test were aimed at speeding up the autoptic analyses on the faces.

The automatic recognition of landmarks chosen for the tests takes advantage of Dlib library. The library is based on $\mathrm{C}++$ language, and it can be used with other programming language such as Python. The library was installed on a Raspberry PI model 4B with Raspberry Pi OS and implemented to detect 68 face landmarks.

The detector was tested on 10 pairs of orthoimages, coloured and not coloured, and the results are not satisfatory although, in a way, promising. The facial landmarks were recognised on 7 pairs of images, but only in 5 cases was the face correcly recognised (Figure 9).

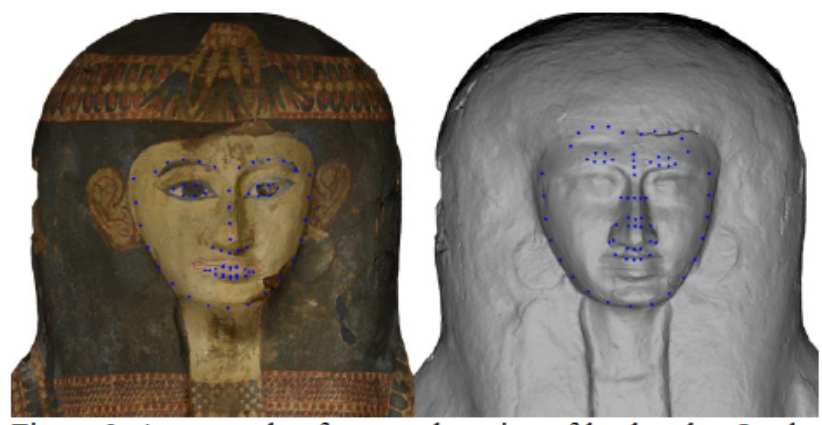

Figure 9. An example of wrong detection of landmarks. On the left, the points are correctly positioned. On the right, the detector failed in finding the position of mouth, nose, eyes, and eyebrows (CRijksmuseum van Oudheden, Leiden). 
In each pair of the 5 cases the position of the landmarks change from the coloured to the not coloured orthoimage. This confirms the extent to which the geometrical shape of the modelled piece of wood is always altered by the pictorial layer. This discrepancy might hint at a reuse - but of course this suggestion must always be validated by further analyses (Figure 10).

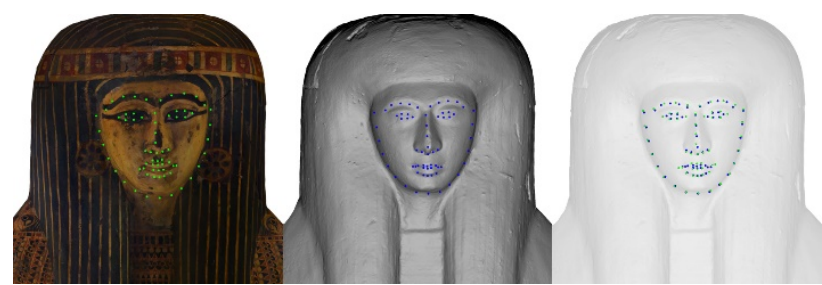

Figure 10. An example of successful detection of facial landmarks. On the right, the points detected on the two orthoimages are compared (C) ‘Museo Egizio', Firenze).

It was noticed also that the results are influenced by the portion of the image analysed. To get better and plausible results the algorythm needs to be trained on large set of similar images. The will of the authors is to test the detector on the remaining coffins and extract the coordinates of the landmarks to evaluate the discrepancies between coloured and not colured orthoimages. These data included in the database could, or not, suggest clues for future studies.

\section{FUTURE DEVELOPMENTS AND WORKS}

After the facial features are measured, the faces will be grouped together on the basis of their similarities, and the variation of different facial components will be computed to understand if there are correlations that may indicate the recurrent presence of specific workshops or may contains clues pointing to a precise historical period. The entire corpus of the selected coffins will be managed in a relational database including all the acquired data, which will be organized into different tables. The last step will be processed in conjunction with the Vatican Coffin Project $(V C P)$ and museums. For this step, the collaboration with the $V C P$ is a unique opportunity to combine data acquired from the most recent and ongoing research on the Yellow Coffins in Europe. Such a collaboration will allow an integration of the data about new (traditional) studies on wood, decoration and paleography, for example, but also with results obtained through other scientific analyses as imaging techniques and analyses of different composition of pigments and materials which can reveal painter's work process, point to pigment origin and trade networks as well as CT-scans and X-rays which allow an easly identification of the density of the plaster. Combining the these data together will give us a wealth of technical information and will allow us to isolate comparative models and to outline a new more precise classification of the Yellow Coffins and their provenance, on the basis of all the constitutive elements of these finds.

Coffins are very complex objects both for their symbolic and religious value and as objects of art. They were subjected to changes during the time in terms of shape, decoration and style as well as to changes of traditions and customs. These complex objects can only be properly studied if we adopt a multidimensional approach, able to encompass as many of their aspects as possible.

\section{ACKNOWLEDGMENTS}

The authors would like to thank the Museums which allowed photogrammetric surveys and consented to the use of the orthophotos of the coffins. Special thanks to Alessia Amenta and all the Vatican Coffin Project team, the curators and the staff of the Museums involved in the Faces Revealed Project for the courtesy and support.

\section{REFERENCES}

Amenta, A., 2014. The Vatican Coffin Project, in: Pischikova E., Budka, J., Griffin, K. (eds), Thebes in the First Millennium BC, 483-99. Cambridge.

Amenta, A., 2018. New results from the CT scanning of a coffin, in: Taylor, J.H., Vandenbeusch, M. (eds), Ancient Egyptian Coffins: Craft, Traditions and Functionality, 323-35. British Museum Publications on Egypt and Sudan 4. Leuven.

Amenta, A., Guichard, H. (eds), 2017. Proceedings of the First Vatican Coffin Conference (Vatican Museums, 19-22 June 2013). Città del Vaticano.

Asensi Amorós, M.V., 2017. The wood of the Third Intermedite perod coffins: The evidence of the analysis for the Vatican Coffin Project", in: Amenta, A., Guichard, H. (eds), Proceedings of the First Vatican Coffin Conference (Vatican Museums, 19-22 June 2013), 45-50, Città del Vaticano.

Aston, D.A., 2009. Burial Assemblages of Dynasty 21-25. Chronology - Typology-Developments, Vienna.

Bryan, B.M., 1987. Portrait Sculpture of Tuthmose IV. Journal of the American Research Center in Egypt, 24, 3-20.

Bryan, B.M., 2010. New Kingdom Sculpture, in: A.B. Lloyd (ed), Companion to Ancient Egypt, 913-43. New York.

Bryan, B.M., 2015. Portraiture, in: Hartwig, M. (ed.), Companion to Ancient Egypt, 375-96.

Cartwright, C., Svoboda, M., 2020. Mummy Portraits of Roman Egypt: Emerging Research from the APPEAR Project. Getty Publications.

Cooney, K.M., 2007. The Cost of Death: The Social and Economic Value of Ancient Egyptian Funerary Art in the Ramesside Period, Leiden.

Cooney, K.M., 2011. Changing Burial Practices at the End of the New Kingdom: Defensive Adaptations in Tomb Commissions, Coffin Commissions, Coffin Decoration, and Mummification. Journal of the American Research Center in Egypt 47: 3-44.

Cooney, K.M., 2014. Ancient Egyptian funerary arts as social documents: Social place, reuse, and working towards a new typology of 21 st Dynasty coffins, in: Sousa, R. (ed.), Body, cosmos, and eternity: New research trends in the iconography and symbolism of ancient Egyptian coffins, 45-66. Oxford.

Cooney, K.M., 2015. Coffins, Cartonnage, and Sarcophagi, in: Hartwig, M. (ed.), A Companion to Ancient Egyptian Art, 26992.

Cooney, K.M., 2017. Coffin reuse: Ritual materialism in the context of scarcity, in: Amenta, A., Guichard, H. (eds), Proceedings of the First Vatican Coffin Conference (Musei Vaticani, 19-22 June 2013), 101-12. Città del Vaticano. 
Cooney, K.M., 2018a. Coffin reuse in Dinasty 21: A case study of the coffins in the British Museum, in: Taylor, J.H., Vandenbeusch, M. (eds), Ancient Egyptian Coffins: Craft, Traditions and Functionality, 295-322. British Museum Publications on Egypt and Sudan 4. Leuven: Peeters Publishers.

Cooney, K.M., 2018b. Patterns of coffin reuse from Dynasties 19 to 22, in: Dawson, J., Strudwick, H. (eds), Ancient Egyptian Coffins: Past - Present - Future, 96-108. Oxford.

Daressy, G., 1900. Les sépultures des prêtes d Ammon à Deir elBahari. Annales Du Service Des Antiquités de l'Égypte, 141-148.

Dawson, J., Strudwick, H. (eds.), 2016. Death on the Nile: Uncovering the Afterlife of Ancient Egypt. London.

Dawson, J., Strudwick, H. (eds.), 2018. Ancient Egyptian Coffins: Past - Present - Future. Oxford.

Gasse, Annie. 1996. Les sarcophages de la Troisième Période Intermédiare du Museo Gregoriano Egizio, Città del Vaticano: Monumenti Musei e Gallerie Pontifici.

Hartwig, M. (ed.), 2015. A Companion to Ancient Egyptian Art.

Laboury, D., 2010. Portrait Versus Ideal Image. UCLA Encyclopedia of Egyptology, 1(1), 1-18.

Mainieri, S. (forthcoming). Photogrammetry and face carvings. Exploring the 'face' of the Egyptian anthropoid coffins by 3Dmodelling. Proceedings of the First International Conference: Ancient Egypt - New Technology, Bloomington, Indiana, March 29-30, 2019.

Mandelli, A., Perfetti, L., Fiorillo, F., Fassi, F., Rossi, C., Greco, C., 2019. The digitalization of ancient egyptian coffins: a discussion over different techniques for recording fine details. Int. Arch. Photogramm. Remote Sens. Spat. Inf. Sci. 42, 743-750. https://doi.org/10.5194/isprs-archives-XLII-2-W15-743-2019.

Meskell, L., 2004. Object Worlds in Ancient Egypt. Material biographies Past and Present.

Nicholson, P.T, Shaw, I. (eds), 2000. Ancient Egyptian Materials and Technologies. Cambridge.

Niwiński, A., 1988. 21st Dynasty Coffins from Thebes: Chronological and Typological Studies. Mainz.
Perdu, Oliver. 2012. Les statues privées de la fin de l'Égypte pharaonique (1069 av. J.-C.- 395 apr. H.-C.). Paris.

Prestipino, G., Santamaria, U., Morresi, F., Amenta, A., Greco, C., 2015. Sperimentazione di adesivi e consolidanti per il restauro di manufatti lignei policromi egizi. In: Atti XIII Congresso Nazionale IGIIC - Lo Stato dell'Arte, Centro di Conservazione e Restauro La Venaria, Torino, 22-24 ottobre 2015, pp. 261-270. Sorouzian, Hourig. 1999. "A bust of Amenophis II at the Kimbell Art Museum". Journal of the American Research Center in Egypt, 28, 55-74.

Prestipino, G., 2017. The Vatican Coffin Project: Observations on the construction tecniques of Third Intermediate Period coffins from the Musei Vaticani, in: Amenta, S., Guichard, H. (eds), Proceedings of the First Vatican Coffin Conference (Musei Vaticani, 19-22 June 2013), 397-406, Città del Vaticano: Edizioni Musei Vaticani.

Sousa, R., 2017. The Tomb of the Priests of Amun at Thebes: The History of the Find, in: Weiss, L. (Ed.), The Coffins of the Priests of Amun: Egyptian Coffins from the 21st Dynasty in the Collection of the National Museum of Antiquities in Leiden. Sidestone Press, Leiden.

Sousa, R., 2018. Gleaming Coffins. Iconography and Symbolism in Theban Coffin Decoration (21st Dynasty), vol. I, Coimbra.

Sousa, R., Amenta, A., Cooney, K.M. (eds), 2021. Bab El-Gasus in Context: Rediscovering the Tomb of the priests of Amun. Roma - Bristol.

Sorouzian, Hourig. 1999. "A bust of Amenophis II at the Kimbell Art Museum". Journal of the American Research Center in Egypt, 28, 55-74.

Taylor, J.H., 1989. Egyptian Coffins, Shire Egyptology 11. Aylesbury.

van Walsem, R0, 1997. The coffin of Djedmonthuiufankh in the National Museum of Antiquitues at Leiden. Leiden.

Weiss, L. (ed.). 2018. The Coffins of the Priests of Amun, Egyptian coffins from the 21st Dynasty in the collection of the National Museum of Antiquities in Leiden. Leiden.

Yaniv, J., Newman, Y., Shamir, A., 2019. The face of art: Landmark detection and geometric style in portraits. ACM Trans. Graph. 38. https://doi.org/10.1145/3306346.3322984. 